\title{
Ultrafiltration in Japanese critically ill patients with acute kidney injury on renal replacement therapy
}

\author{
Koichi Kitamura' ${ }^{1}$ Koichi Hayashi ${ }^{2}$, Shigeki Fujitani ${ }^{2}$, Raghavan Murugan ${ }^{3,4}$ and Toshihiko Suzuki ${ }^{*}$ [D
}

\begin{abstract}
A recent worldwide survey indicates an international diversity in net ultrafiltration (UF ${ }^{\mathrm{NET}}$ ) practices for the treatment of fluid overload in critically ill patients with acute kidney injury (AKI) requiring renal replacement therapy (RRT). The sub-analysis of the survey has demonstrated that maximum doses of furosemide used before determination of diuretic resistance are lower in Japan than those prescribed worldwide and UFFET is lower but is initiated earlier. In contrast, the interval during which practitioners evaluate fluid balance is longer. The characterization of RRT in critically ill patients in Japan should unveil more appropriate approaches to the successful treatment of AKI.
\end{abstract}

Keywords: Net ultrafiltration, Diuretics, Fluid overload, Renal replacement therapy

\section{Letter to the editor}

\section{Introduction}

Although renal replacement therapy (RRT) is an indispensable modality for the treatment of acute kidney injury (AKI), there have been no definitive guidelines for the appropriate management of fluid overload in critically ill patients with AKI. Recently, Murugan et al. [1] conducted a questionnaire-based worldwide survey and demonstrated wide variations of practice in net ultrafiltration $\left(\mathrm{UF}^{\mathrm{NET}}\right)$ prescription and practice. We had an opportunity to obtain the data reported by Japanese practitioners that constituted a part of the multinational results [1].

\footnotetext{
*Correspondence: toshihikos@jadecom.jp

${ }^{1}$ Department of Nephrology, Endocrinology and Diabetes, Tokyo Bay

Urayasu Ichikawa Medical Center, 3-4-32 Todaijima, Urayasu, Chiba 279-0001, Japan

Full list of author information is available at the end of the article
}

\section{Methods}

We evaluated the $\mathrm{UF}^{\mathrm{NET}}$ practice (timing of UF ${ }^{\mathrm{NET}}$ initiation/UF ${ }^{\mathrm{NET}}$ prescription) and the doses of diuretics in Japan. The results were compared with the multinational (not including Japan) survey.

\section{Results}

We found a marked difference in the use of diuretics between these surveys. In the multinational survey, $41.1 \%$ of the practitioners used furosemide at a maximum dose of $250 \mathrm{mg} /$ day or higher before determining diuretic resistance (Fig. 1). In contrast, 91.3\% of Japanese doctors prescribed it at maximum doses lower than $250 \mathrm{mg} /$ day.

Table 1 shows that $50.9 \%$ of the multinational respondents would start $\mathrm{UF}^{\mathrm{NET}}$ after identifying persistent ( $\geq 12 \mathrm{~h}$ ) oliguria/anuria; in Japan, only $26.6 \%$ of the practitioners commence UF ${ }^{\mathrm{NET}}$ after persistent oliguria/anuria. Although hemodynamic status and cumulative fluid balance constitute two major determinants of the UF ${ }^{\mathrm{NET}}$ prescription in both Japan and the world, $13.8 \%$ of Japanese practitioners pay priority attention to weight gain as a result of total fluid homeostasis. original author(s) and the source, provide a link to the Creative Commons licence, and indicate if changes were made. The images or other third party material in this article are included in the article's Creative Commons licence, unless indicated otherwise in a credit line to the material. If material is not included in the article's Creative Commons licence and your intended use is not permitted by statutory regulation or exceeds the permitted use, you will need to obtain permission directly from the copyright holder. To view a copy of this licence, visit http://creativecommons.org/licenses/by/4.0/. The Creative Commons Public Domain Dedication waiver (http://creativecommons.org/publicdomain/zero/1.0/) applies to the data made available in this article, unless otherwise stated in a credit line to the data. 


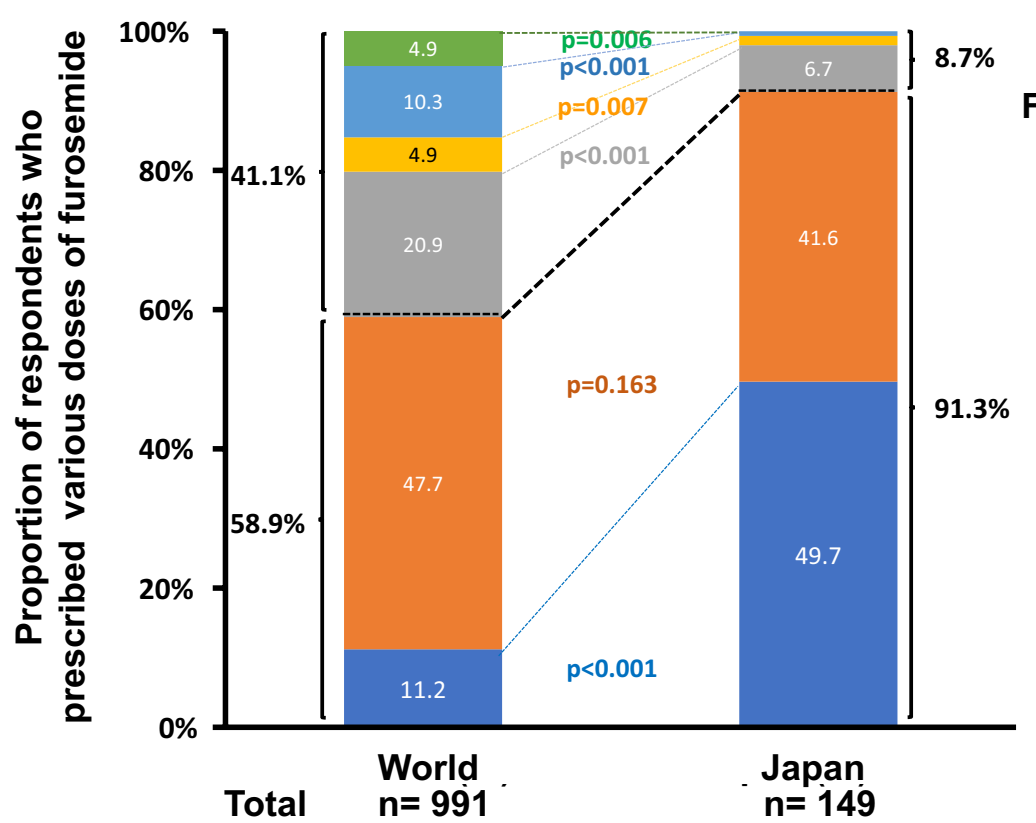

\section{Furosemide doses \\ $>1,000$ \\ 750-1,000 \\ 500-750 \\ 250-500 \\ 100-250 \\ - $<100$ (mg/day)} $n=149$

Fig. 1 Maximum doses of furosemide prescribed by survey practitioners. Statistical analyses were performed using the Chi-square test or Fisher's exact test, as appropriate. Evaluation between two cohort groups (world vs. Japan) was conducted using a two-proportion z test

In the worldwide survey, UF ${ }^{\mathrm{NET}}$ was controlled by altering ultrafiltration rate or modulating both ultrafiltration and replacement fluid rate for hemodynamically unstable patients (Table 1). In Japan, however, fewer practitioners modified both parameters (31.7\% vs. $46.0 \%)$. Finally, there observed was a marked variation in the frequency with which practitioners checked fluid balance during continuous RRT; hourly $\mathrm{UF}^{\mathrm{NET}}$ evaluations were conducted by $35.8 \%$ of multinational but by only $21.9 \%$ of Japanese practitioners.

\section{Discussion}

This sub-analysis unveiled that most of the Japanese doctors prescribed furosemide at maximum doses lower than $250 \mathrm{mg} /$ day whereas the multinational survey [1] as well as the sub-analysis from Europe [2] showed the prescription of a maximum $250 \mathrm{mg} /$ day or higher by $41.1-56.1 \%$ of physicians. Notably, in a study of acute heart failure management in Japan, the maximum dose of furosemide $(\leq 200 \mathrm{mg} /$ day) was less than half the dose used in the USA [3], which was expected to cause lower mortality [4]. In AKI, large doses of furosemide may cause ototoxicity [5] and, along with the prolonged infusion to delay dialysis, may be associated with a higher mortality [6].

Most practitioners $(90.0 \%)$ across the world agree that early $\mathrm{UF}^{\mathrm{NET}}$ is beneficial [1]. The present study suggests earlier implementation of UF ${ }^{\mathrm{NET}}$ in Japan than in the world, possibly because Japanese practitioners have made early decision of diuretic resistance and recognition of weight gain resulting in identifying persistent oliguria/ anuria in less than $12 \mathrm{~h}$. It may fairly be presumed that early $\mathrm{UF}^{\mathrm{NET}}$ initiation facilitates well-balanced fluid homeostasis and enables simultaneous administration of fluid volumes, including medications and nutrition [7]. Caveat is in order since there exists some controversy regarding the aggressive fluid management in critically ill patient $[8,9]$.

The $\mathrm{UF}^{\mathrm{NET}}$ rate prescription is reported to be lower in Japan $[40.0 \mathrm{~mL} / \mathrm{h}]$ than in the worldwide survey $[80.0 \mathrm{~mL} / \mathrm{h}][1]$. There is an observational study suggesting J-shaped association between $\mathrm{UF}^{\mathrm{NET}}$ rate and mortality in critically ill patients receiving RRT [10]; UF ${ }^{\mathrm{NET}}$ rate between 1.01 and $1.75 \mathrm{~mL} / \mathrm{kg} / \mathrm{h}$ is associated with the lowest risk of death. Naorungroj et al. [11] have also shown that early $\mathrm{UF}^{\mathrm{NET}}$ rate $<1.01 \mathrm{~mL} / \mathrm{kg} / \mathrm{h}$ is associated with decreased mortality when compared with early $\mathrm{UF}^{\mathrm{NET}}$ rate $>1.75 \mathrm{~mL} / \mathrm{kg} / \mathrm{h}$. Our survey and the original study by Murugan [1] evaluate $\mathrm{UF}^{\mathrm{NET}}$ rate on the basis of $\mathrm{mL} / \mathrm{h}$, but if we assume the body weight of Japanese population as $57 \mathrm{~kg}$ (https://www.mhlw.go.jp/toukei/ youran/indexyk_2_1.html), the UF ${ }^{\mathrm{NET}}$ rate in Japanese population should be $0.7 \mathrm{~mL} / \mathrm{kg} / \mathrm{h}$. Furthermore, there is a difference in the way of controlling $\mathrm{UF}^{\mathrm{NET}}$ (altering ultrafiltration rate or modulating both ultrafiltration and replacement fluid rate) between the world-wide survey and Japan; fewer Japanese practitioners attempted to modify both parameters than those among the worldwide survey. This difference might be attributed to the smaller 
Table 1 Comparison of parameters associated with UF ${ }^{N E T}$ between world and Japan

\begin{tabular}{|c|c|c|c|}
\hline & World (not including Japan) & Japan & $p$ value \\
\hline \multicolumn{4}{|l|}{ Q-1. Criteria used for UF $F^{\mathrm{NET}}$ initiation, $N(\%)$} \\
\hline (a) Persistent oliguria/anuria (urine output $<0.5 \mathrm{~mL} / \mathrm{kg} / \mathrm{h}$ for $\geq 12 \mathrm{~h}$ ) & $477(50.9)$ & $38(26.6)$ & $<0.001$ \\
\hline (b) Severe hypoxemia $\left(\mathrm{PaO}_{2} / \mathrm{FIO}_{2}\right.$ ratio < 150) & $134(14.3)$ & $18(12.6)$ & 0.586 \\
\hline (c) Pulmonary edema with or without hypoxemia & $162(17.3)$ & $32(22.4)$ & 0.138 \\
\hline (d) Cumulative fluid balance (> $1000 \mathrm{~mL}$ ) & $51(5.4)$ & $3(2.1)$ & 0.088 \\
\hline (e) Fluid overload $>10 \%$ of body weight & $57(6.1)$ & $3(2.1)$ & 0.053 \\
\hline (f) Ongoing need for fluids in the presence of oliguria & $57(6.1)$ & $49(34.3)$ & $<0.001$ \\
\hline Total & 938 & 143 & \\
\hline \multicolumn{4}{|l|}{ Q-2. Criteria used for UF ${ }^{N E T}$ prescription, $N(\%)$} \\
\hline (a) 24-h fluid balance & $148(14.8)$ & $8(5.3)$ & 0.001 \\
\hline (b) Cumulative fluid balance & $201(20.1)$ & $29(19.1)$ & 0.765 \\
\hline (c) Weight gain & $48(4.8)$ & $21(13.8)$ & $<0.001$ \\
\hline (d) Radiographic features of fluid overload & $21(2.1)$ & $10(6.6)$ & 0.002 \\
\hline (e) Hemodynamic status (HR, BP, CVP, PPV, dose of vasopressors) & $552(55.3)$ & $82(53.9)$ & 0.763 \\
\hline (f) Volume of anticipated fluid use in the next $24 \mathrm{~h}$ & $22(2.2)$ & $1(0.7)$ & 0.205 \\
\hline (g) Arterial lactate & $7(0.7)$ & $1(0.7)$ & 0.953 \\
\hline Total & 999 & 152 & \\
\hline \multicolumn{4}{|l|}{ Q-3. Method used to achieve UF ${ }^{\text {NET }}$ using CRRT, N (\%) } \\
\hline (a) By varying ultrafiltration rate only & $536(48.6)$ & $77(54.2)$ & 0.203 \\
\hline (b) By varying replacement fluid rate only & $60(5.4)$ & $20(14.1)$ & $<0.001$ \\
\hline (c) By varying both ultrafiltration and replacement fluid rate & $508(46.0)$ & $45(31.7)$ & 0.001 \\
\hline Total & 1104 & 142 & \\
\hline \multicolumn{4}{|l|}{ Q-4. How frequently did you check net fluid balance during CRRT? N (\%) } \\
\hline (a) $\leq$ Every $1 \mathrm{~h}$ & $409(35.8)$ & $32(21.9)$ & $<0.001$ \\
\hline (b) $\leq$ Every $2 \mathrm{~h}$ & $511(44.8)$ & $60(41.1)$ & 0.398 \\
\hline (c) $\leq$ Every $4 \mathrm{~h}$ & $660(57.8)$ & $89(61.0)$ & 0.473 \\
\hline (d) $\leq$ Every $6 \mathrm{~h}$ & $772(67.7)$ & $104(71.2)$ & 0.383 \\
\hline (e) $\leq$ Every $8 \mathrm{~h}$ & $884(77.5)$ & $127(87.0)$ & 0.009 \\
\hline (f) $\leq$ Every $12 \mathrm{~h}$ & $1015(89.0)$ & $136(93.2)$ & 0.121 \\
\hline (g) $\leq$ Every $24 \mathrm{~h}$ & $1141(100)$ & $146(100)$ & na \\
\hline
\end{tabular}

Statistical analyses were performed using the Chi-square test or Fisher's exact test, as appropriate na not applicable

anthropometric characteristics of Japanese patients or relatively less requirement of replacement fluid exchange due to early introduction of ultrafiltration. The association between low UF ${ }^{\mathrm{NET}}$ and mortality in Japan needs to be more thoroughly investigated.

Finally, this survey found that Japanese practitioners evaluated net fluid balance less frequently. The reason for this difference might be that constraints of staffing affect the timing of evaluation of $\mathrm{UF}^{\mathrm{NET}}$ balance. This important issue requires urgent improvement.

There exist substantial worldwide or practitionerdependent variations in $\mathrm{UF}^{\mathrm{NET}}$ strategies for AKI patients. Under the current status, where the strategy for the RRT in critically ill patients is not highly organized yet, well-defined approaches to RRT, including evidence-based guidelines, are required to offer more favorable treatment to critically ill patients with AKI and consequently, to obtain more consistent results.

\footnotetext{
Abbreviations

AKI: Acute kidney injury; RRT: Renal replacement therapy; UF ${ }^{\mathrm{NET}}$ : Net ultrafiltration rate.

\section{Acknowledgements}

None.

Authors' contributions

KK drafted the manuscript and all other members have equally supervised the manuscript. All authors read and approved the final manuscript.
} 


\section{Funding \\ None.}

\section{Availability of data and materials}

Data sharing is not applicable to this article as no datasets were generated or analyzed during the current study.

\section{Declarations}

Ethics approval and consent to participate

The multinational study was approved by the University of Pittsburgh's Human Research Protection Office.

\section{Consent for publication}

Completing the survey by critical care practitioners implied voluntary consent. No patients were studied in this survey.

\section{Competing interests}

The authors declare that they have no competing interests.

\section{Author details}

${ }^{1}$ Department of Nephrology, Endocrinology and Diabetes, Tokyo Bay Urayasu Ichikawa Medical Center, 3-4-32 Todaijima, Urayasu, Chiba 279-0001, Japan. ${ }^{2}$ Department of Emergency and Critical Care Medicine, St. Marianna University School of Medicine, Kanagawa, Japan. ${ }^{3}$ The Center for Critical Care Nephrology, Department of Critical Care Medicine, University of Pittsburgh School of Medicine, Pittsburgh, PA, USA. ${ }^{4}$ The Clinical Research, Investigation, and Systems Modeling of Acute Illness (CRISMA) Center, Department of Critical Care Medicine, University of Pittsburgh School of Medicine, Pittsburgh, PA, USA.

Received: 14 October 2021 Accepted: 7 December 2021

Published online: 20 December 2021

\section{References}

1. Murugan R, Ostermann M, Peng Z, Kitamura K, Fujitani S, Romagnoli S, Di Lullo L, Srisawat N, Todi S, Ramakrishnan N, Hoste E, Puttarajappa CM, Bagshaw SM, Weisbord S, Palevsky PM, Kellum JA, Bellomo R, Ronco C. Net ultrafiltration prescription and practice among critically ill patients receiving renal replacement therapy: a multinational survey of critical care practitioners. Crit Care Med. 2020;48(2):e87-97. https://doi.org/10. 1097/CCM.0000000000004092.
2. Lumlertgul N, Murugan R, Seylanova N, McCready P, Ostermann M. Net ultrafiltration prescription survey in Europe. BMC Nephrol. 2020;21:522. https://doi.org/10.1186/s12882-020-02184-y.

3. Tanaka TD, Sawano M, Friedman M, Kohsaka S. Acute heart failure management in the USA and Japan: overview of practice patterns and review of evidence. ESC Heart Fail. 2018;5:932-48. https://doi.org/10.1002/ehf2. 12305.

4. Hasselblad V, Stough WG, Shah MR, Lokhnygina Y, O'Conner CM, Califf RM, Adams KF Jr. Relation between dose of loop diuretics and outcomes in a heart failure population: results of the ESCAPE trial. Eur J Heart Fail. 2007;9:1064-9. https://doi.org/10.1016/j.ejheart.2007.07.011.

5. Ho KM, Sheridan DJ. Meta-analysis of furosemide to prevent or treat acute renal failure. BMJ. 2006;333:420-5. https://doi.org/10.1136/bmj. 38902.605347.7C.

6. Ho KM, Power BM. Benefits and risks of furosemide in acute kidney injury. Anaesthesia. 2010;65:283-93. https://doi.org/10.1111/j.365-2044.2009. 06228.x.

7. Murugan R, Bellomo R, Palevsky PM, Kellum JA. Ultrafiltration in critically ill patients treated with kidney replacement therapy. Nat Rev Nephrol. 2021;17:262-76. https://doi.org/10.1038/s41581-020-00358-3.

8. Hayakawa K. Aggressive fluid management in the critically ill: Pro. J Intensive Care. 2019;7:9. https://doi.org/10.1186/s40560-019-0361-9.

9. Morisawa K, Fujitani S, Taira Y. The downside of aggressive volume administration in critically ill patients-"aggressive" may lead to "excessive." J Intensive Care. 2019;7:10. https://doi.org/10.1186/s40560-019-0360-x.

10. Murugan R, Kerti SJ, Chang CH, Gallagher M, Clermont G, Palevsky PM, Kellum JA, Bellomo R. Association of net ultrafiltration rate with mortality among critically ill adults with acute kidney injury receiving continuous venovenous hemodiafiltration: a secondary analysis of the randomized evaluation of normal vs augmented level (RENAL) of renal replacement therapy trial. JAMA Netw Open. 2019;2(6):e195418. https://doi.org/10. 1001/jamanetworkopen.2019.5418.

11. Naorungroj T, Neto AS, Zwalman-Hessels L, Yanase F, Estwood G, Murugan R, Kellum JA, Bellomo R. Early net ultrafiltration rate and mortality in critically ill patients receiving continuous renal replacement therapy. Nephrol Dial Transplant. 2021;36:1112-9. https://doi.org/10.1093/ndt/ gfaa032.

\section{Publisher's Note}

Springer Nature remains neutral with regard to jurisdictional claims in published maps and institutional affiliations.
Ready to submit your research? Choose BMC and benefit from:

- fast, convenient online submission

- thorough peer review by experienced researchers in your field

- rapid publication on acceptance

- support for research data, including large and complex data types

- gold Open Access which fosters wider collaboration and increased citations

- maximum visibility for your research: over 100M website views per year

At BMC, research is always in progress.

Learn more biomedcentral.com/submissions 